\title{
A method based on circumferential strain distribution for roller path design in conventional spinning of thin-walled conical part with curved surface
}

\author{
Yongdi Wang \\ Northwestern Polytechnical University \\ Hongwei Li \\ Northwestern Polytechnical University \\ Pengfei Gao ( $\sim$ gaopengfei@nwpu.edu.cn ) \\ Northwestern Polytechnical University \\ Mei Zhan \\ Northwestern Polytechnical University \\ Xinggang Yan \\ Northwestern Polytechnical University \\ Haotong Niu \\ Northwestern Polytechnical University
}

\section{Research Article}

Keywords: Curved cone part, Conventional spinning, Roller path design, Circumferential strain distribution

Posted Date: November 19th, 2021

DOI: https://doi.org/10.21203/rs.3.rs-1081467/v1

License: (c) (1) This work is licensed under a Creative Commons Attribution 4.0 International License.

Read Full License

Version of Record: A version of this preprint was published at The International Journal of Advanced Manufacturing Technology on January 12th, 2022. See the published version at https://doi.org/10.1007/s00170-022-08661-y. 


\title{
A method based on circumferential strain distribution for roller path design in
} conventional spinning of thin-walled conical part with curved surface

\author{
Yongdi Wang, Hongwei Li, Pengfei Gao *, Mei Zhan, Xinggang Yan, Haotong Niu
}

State Key Laboratory of Solidification Processing, Shaanxi Key Laboratory of High-Performance

Precision Forming Technology and Equipment, School of Materials

Science and Engineering, Northwestern Polytechnical University

P.O. Box 542, Xi'an, Shaanxi 710072, PR China

*Corresponding author.

E-mail address: E-mail address: gaopengfei@,nwpu.edu.cn (Pengfei Gao)

\begin{abstract}
Multi-pass conventional spinning is the preferable forming technology for the forming of thinwalled conical part with curved surface (TCPCS) in aerospace field. In multi-pass conventional spinning, the design of roller path is a critical problem due to its sensitive effect on the deformation mode and forming defect during spinning process. However, at present, the roller path is still mainly designed based on experience and trial-and-error, which seriously restricts the high-performance spinning of TCPCS. In this work, a new quantitative method based on circumferential strain distribution was developed for the roller path design in multi-pass conventional spinning of TCPCS. In this method, the total required circumferential strain for the forming of final TCPCS by conventional spinning was firstly determined. Then, the spinning passes number were obtained through dividing the total required circumferential strain by the ultimate circumferential strain producing the spinning instability $\left(\varepsilon_{\theta u l t}\right)$. As for the roller path
\end{abstract}


profile in each pass, it is divided into two sections and determined respectively, i.e. the attaching mandrel section and the performing section. The attaching mandrel section presents the same profile of mandrel. The profile of preforming section is determined point-by-point by distributing the rest of circumferential strain $\left\{\varepsilon_{\theta \mathrm{ni}}\right\}$ to produce the final TCPCS. The point-by-point distributed circumferential strain is half of the $\left\{\varepsilon_{\theta n i}\right\}$ at the initial stage until reaches the half of $\varepsilon_{\theta u l t}$, then it will keep the half of $\varepsilon_{\theta u l t}$ to the end. The proposed new method of roller path design was validated by finite element simulation, where well spinning stability, wall thickness distribution and roundness were obtained. This method provides a quantitative, high-efficient and universal way for the roller path design in conventional spinning of

\section{TCPCS.}

Key words: Curved cone part; Conventional spinning; Roller path design; Circumferential strain distribution

\section{Introduction}

With the rapid development of aerospace and other high-tech industries, thin-walled complex parts with significant structural benefits are urgently needed in advanced aerospace equipment to reduce mass and improve overall performance [1]. Superalloy thin-walled conical part with curved surface (TCPCS) is such a typical component. However, due to the large deformation resistance of superalloy and the complex structure characteristics, it is necessary to select a reasonable forming process to achieve highperformance forming of these components. The possible forming processes of this kind of components generally includes block welding, deep drawing and multi-pass conventional spinning. Compared with the former two forming processes, the multi-pass conventional spinning has the advantages of high precision, good performance, high material utilization, low cost, small forming force and high process flexibility, which is the most potential way to form these components [2, 3]. 
In the multi-pass conventional spinning process, the workpiece rotates along with the mandrel and the roller exerts local point loading along the specific roller path to produce the continuous local deformation, which gradually realize the integral forming of the component. It can be seen that the roller path is one of the most important parameters, which has crucial impact on the forming stability $[4,5]$. Some studies have shown that unreasonable roller path will lead to cracks, flange wrinkles and other defects $[6,7]$. Because the roller path is a complex curve with high flexibility, its optimization design is very difficult [8]. In addition, the TCPCS usually has the characteristics of extreme size and specialshaped curved surface, which further increases the difficulty of the design of the roller path. Therefore, it is of great significance to study the design method of roller path for the multi-pass conventional spinning of TCPCS.

At present, some researches have been attempted on the influence of roller path on forming quality. Liu et al.[9] investigated the influence of straight line, arc and involute roller path on the distribution of equivalent stress and strain, and found that the stress and strain were smaller under the involute roller path; Hayama et al. [10] found that compared with the straight and convex curve roller path, the spinning forming stability is the best and the flange is not easy to fluctuate under concave curve roller path. Long et al. [11] Studied the influences of concave-convex curve, concave curve, convex curve and straight line roller path on spinning forming force and wall thickness. It was shown that the spinning force of concave curve was the largest, while the convex curve roller path was beneficial to suppress the wall thickness reduction. James et al. [12] selected B-spline curve as the spinning roller path to study the effects of four characteristic parameters of roller path profile on forming quality. The results indicated that the roller path with larger curvature is conducive to maintaining constant spinning force and the stability of flange state during spinning. The above studies have preliminarily studied the influence of single pass roller 
path on the forming results qualitatively, but not illustrated the design method of the total roller path in the whole spinning process.

In the aspect of roller path design for the spinning process, Chen et al. [13] proposed a design method of evenly spaced multi-pass involute roller path for the spinning process of cylindrical parts, while the base circle radius and the number of passes of involute path were given based on experience. Liu et al. [14] analyzed the multi-pass spinning process of the head with arc and straight generatrix. In their work, the involute roller path was used, whose design was given based on the establishment of the relationship between involute roller parameters and component diameter. However, the method of determined involute roller path is complex and lack of effectiveness verification. In view of the conventional spinning process of components with curved surface, the principle of circumferential strain uniform distribution between passes is proposed and proved by Guo et al. [15], which is beneficial to improve the forming accuracy and provides a theoretical basis for roller path design. However, the pass number and length of attaching mandrel path are determined by experience, and the influence of these two parameters on the forming quality is not specifically explored. In addition, the roller path profile is a specified type of concave curve, and only considers the circumferential strain distribution between passes while ignores the circumferential strain distribution within the pass. Gao et al. [16] put forward a parametric roller path design method for curvilinear generatrix parts. Three different types of control point allocation for the spinning roller path are designed, which makes the roller path profile change. Huang et al. [17] proposed a asymptotic forming roller path generation method for general circular arc cross-section parts, which means each pass is close to the component contour, and the attaching mandrel forming is not carried out until the last pass. It is easy to cause work hardening of material and reduce the wall thickness excessively for TCPCS. However, the method of roller path profile by dividing the 
circumferential strain of each point equally has important inspiration. To sum up, the above methods have some guidance for roller path design. However, in the above works, the roller path number and profile are strongly dependent on the experience and the certain type of curve respectively, presenting limited universality. Therefore, it is needed to develop a new roller path design method with quantitative basis and independent of specific curve type.

The purpose of this paper is to propose a design method based on distribution of circumferential strain for roller path of conventional spinning. This method includes the determination of the number and position of spinning passes and the calculation of roller path profile. Then, the reliability of this method is verified. This method provides a quantitative, high-efficient and universal way for the roller path design in conventional spinning of TCPCS.

\section{The design method for roller path}

\subsection{Geometrical feature of the conical part and roller path}

As shown in Fig. 1, the contour line of the TCPCS is composed of four segments: $30^{\circ}$ cone segment, $\mathrm{R} 500$ arc segment, $18^{\circ}$ cone segment and R 350 arc segment. The wall thickness is $0.8 \mathrm{~mm}$. Because there is no change of half cone angle in $30^{\circ}$ cone section, the shear spinning process can be used and the roller path is easy to get. The half cone angle of the remaining three sections decreases gradually to $10^{\circ}$.

If the remaining three sections are formed by shear spinning, it is easy to cause excessive thinning, fracture and wrinkle due to large local deformation. Thus, the multi-pass conventional spinning is applied in the remaining three sections, which is helpful to solve above problems. For the multi-pass conventional spinning section, roller path is the most key parameters, whose design method is focused in this study.

Fig. 1 shows the diagram roller path for conventional spinning. In this research, the desigin of roller 
path includes the determination of pass number $n$, the profile and the position of each pass. The roller path in each pass is divided into the attaching mandrel section and the preforming section according to their different functions in the forming process. The attaching mandrel section is shown by the green line which is the section between the starting points of two adjacent passes. In addition, the preforming section is further divided into two sections: the attaching mandrel section in next pass (AMSNP) and the non-attaching mandrel section in next pass (NMSNP) which are represented by the red and blue line respectively. Subsequently, the design method for roller path will be described from two aspects the determinations of the number $n$ and position of spinning passes and the roller path profile.

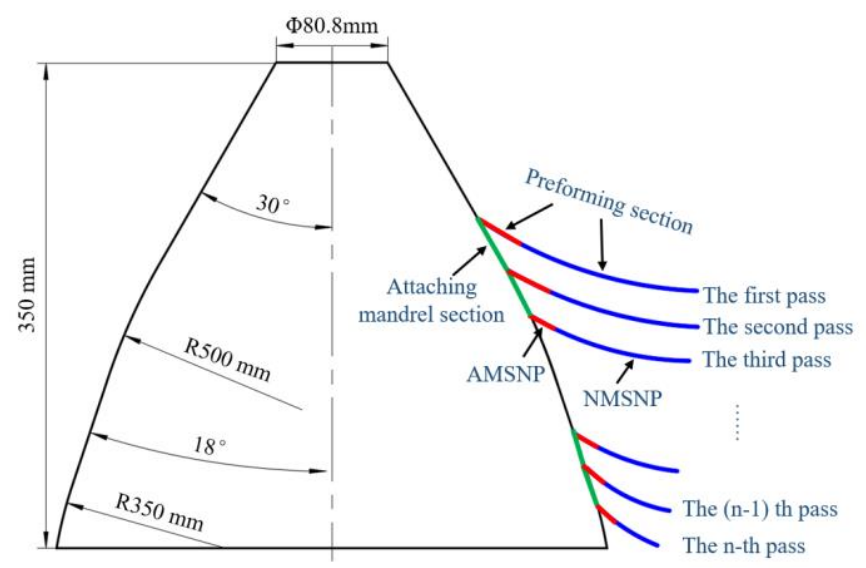

Fig. 1 Schematic of the geometry of TCPCS and roller path diagram

\subsection{Determination of the number and start position of spinning passeses}

The number of spinning passes is a key parameter in the roller path design. Too many passes will lead to excessive work hardening and thickness reduction. However, too few passes will cause instability in the spinning process. It is well known that wall thickness changes little in conventional spinning, which means the thickness strain can be ignored. Because the volume remains unchanged during deformation, the sum of circumferential strain and radial strain is zero. Circumferential strain plays great roles in the deformation during conventional spinning. Thus, the circumferential strain is used as deformation index 
for roller path design in this work. If the circumferential strain is too large during a spinning pass, the component is easy to wrinkle. Therefore, it is necessary to limit the circumferential strain. So, various linear roller paths with different circumferential strains were conducted to determine the ultimate circumferential strain $\left(\varepsilon_{\theta u l t}\right)$ by testing wrinkling degree. It is found that when the circumferential strain is no more than 0.025 , there is no serious wrinkling of the blank. Thus, 0.025 is applied as the ultimate circumferential strain $\varepsilon_{\theta u l t}$ in this research.

In order to determine the number and start position of spinning passes, the required circumferential strain point by point in conventional spinning is needed to calculate. The premise of obtaining the circumferential strain point by point is to get the relationship between the points on the contour line of component and the corresponding points on the workpiece after shear spinning. As shown in Fig. 2, the axis of the mandrel is $y$-axis and the radius of the bottom perpendicular to the mandrel axis is regarded as the $x$-axis. To get the relationship between the points on the workpiece and the corresponding on the contour after forming, the contour and workpiece are discretized into micro elements along the contour line and workpiece radius, respectively. The points on the contour line of component are represented by $P(x, y)$, and the point set is $\left\{\left(x_{0}, y_{0}\right),\left(x_{1}, y_{1}\right) \ldots \ldots\left(x_{\mathrm{i}}, y_{\mathrm{i}}\right) \ldots \ldots\right\}$. The corresponding points on the workpiece are represented by $P^{\prime}\left(x^{\prime}, y^{\prime}\right)$ and the set of points is $\left\{\left(x_{0}^{\prime}, y_{0}^{\prime}\right),\left(x_{1}^{\prime}, y_{1}^{\prime}\right) \ldots \ldots\left(x_{\mathrm{i}}^{\prime}, y_{\mathrm{i}}^{\prime}\right) \ldots \ldots\right\}$. The coordinates of any two adjacent points are represented by $P_{\mathrm{i}-1}^{\prime}\left(x_{\mathrm{i}-1}^{\prime}, y_{\mathrm{i}-1}^{\prime}\right), P_{\mathrm{i}}^{\prime}\left(x_{\mathrm{i}}^{\prime}, y_{\mathrm{i}}^{\prime}\right)$ and $P_{\mathrm{i}-1}\left(x_{\mathrm{i}-1}, y_{\mathrm{i}-1}\right), P_{\mathrm{i}}\left(x_{\mathrm{i}}, y_{\mathrm{i}}\right)$ at workpiece and the contour line respectively, as shown in Fig. 2. Assuming that the thickness is constant ( $t_{0}=t, t_{0}$ and $t$ is the initial and deformed wall thickness respectively) in conventional spinning process, and combining with the volume invariance principle in plastic deformation, which means the volume of the ring before deformation is equal to that of the frustum ring after deformation, the Eq. (1) can be obtained. Thus, the coordinates of any two adjacent points have the 
following relationship as shown in Eq. (2). Because the coordinates of the starting point are the same, the

Eq. (3) can be obtained.

$$
\begin{gathered}
\left.\left(x_{\mathrm{i}}^{\prime 2}-x_{\mathrm{i}-1}^{\prime 2}\right) t_{0} \pi=\pi t \sqrt{\left(x_{\mathrm{i}}-x_{\mathrm{i}-1}\right)^{2}+\left(y_{\mathrm{i}}-y_{\mathrm{i}-1}\right.}\right)^{2} \times\left(x_{\mathrm{i}}+x_{\mathrm{i}-1}\right) \\
x_{\mathrm{i}}^{\prime}=\sqrt{\left.\sqrt{\left(x_{\mathrm{i}}-x_{\mathrm{i}-1}\right)^{2}+\left(y_{\mathrm{i}}-y_{\mathrm{i}-1}\right.}\right)^{2} \times\left(x_{\mathrm{i}}+x_{\mathrm{i}-1}\right)+x_{\mathrm{i}-1}^{\prime 2}} \\
x_{0}=x_{0}^{\prime}, y_{0}=y_{0}^{\prime} \\
\varepsilon_{\theta 1 t}=\ln \frac{x_{\mathrm{i}}}{x_{\mathrm{i}}^{\prime}}
\end{gathered}
$$

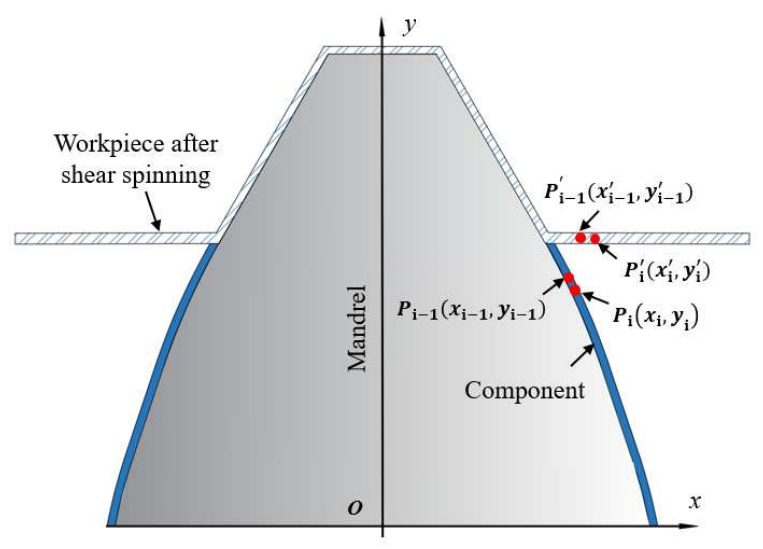

Fig. 2 Schematic diagram of the relationship between the point on the workpiece and component

Then, by substituting Eq. (2) and (3) into Eq. (4), the circumferential strain at any point on the outline during the forming of final TCPCS from the workpiece after shear spinning is determined. The rest of circumferential strain is recorded as a set $\left\{\varepsilon_{\theta 11}, \varepsilon_{\theta 12} \ldots \ldots \varepsilon_{\theta 11} \ldots \ldots\right\}$, in which the " 1 ” in the second subscript represents the first pass, and the " $\mathrm{i}$ ” in the third subscript indicates the $i$-th point. The distribution law of $\left\{\varepsilon_{\theta 11}, \varepsilon_{\theta 12} \ldots \ldots \varepsilon_{\theta 1 i} \ldots ..\right\}$ is shown in Fig. 3(a). It can be seen that, with the increase of $X$, the circumferential strain increases gradually. The maxmium circumferential strain occurs at the larger diameter section of the component, which is the total circumferential strain required to complete the final forming of the component and recorded as $\varepsilon_{\theta 1 \max }$. 
(a)

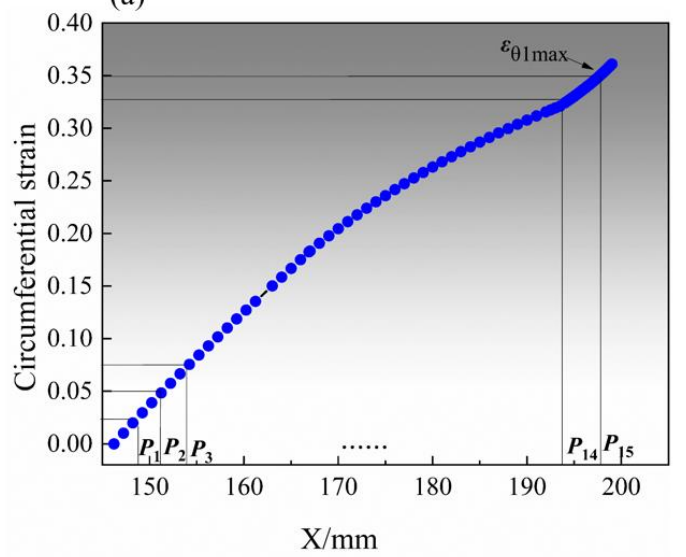

(b)

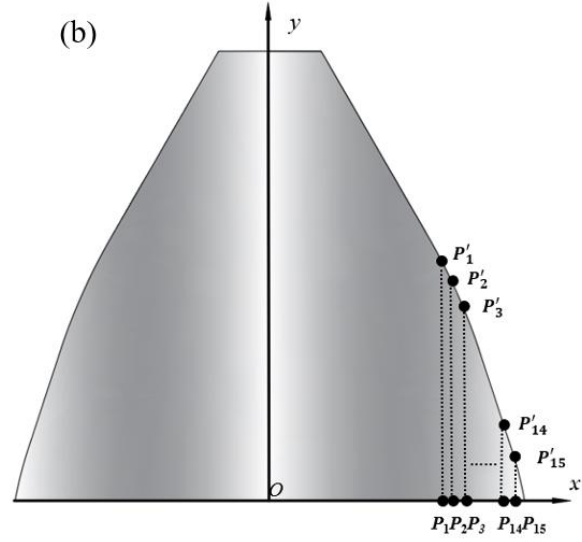

Fig. 3 Schematic diagram for the determination of spinning passes and the corresponding start position:

(a) distribution of circumferential strain along $\mathrm{X}$-axis; (b) the start position of each roller pass.

The determination of spinning pass number $n$ is based on the principle that making the circumferential strain of each pass is equal, and the value of circumferential strain is as large as possible while can not exceed the ultimate circumferential strain. Therefore, when the circumferential strain of each pass is equal to the ultimate circumferential strain, the number of passes in the whole spinning process is the least. Thus, the number of passes is calculated by Eq. (5). According to Eq. (4), the maximum circumferential strain $\varepsilon_{\theta \max }$ is 0.3522 , and the ultimate circumferential strain $\varepsilon_{\theta u l t}$ is 0.025 , so the number of passes $n$ is 15 .

$$
n=\left\lceil\frac{\varepsilon_{\theta 1 \mathrm{max}}}{\varepsilon_{\theta \mathrm{ult}}}\right\rceil
$$

Partition the circumferential strain $\left\{\varepsilon_{\theta 11}, \varepsilon_{\theta 12} \ldots \ldots \varepsilon_{\theta 1 \mathrm{i}} \ldots \ldots\right\}$ in Fig.3 (a) with an interval of 0.025 , the point of $P_{1}$ to $P_{15}$ can be determined as the positions of the entry points of 15 passes in X-axis. The intersections of the contour line and the vertical line are the position of the start point of each pass on the contour line, as indicated by point $P_{1}^{\prime}$ to $P_{15}^{\prime}$ in Fig.3 (b). In addition, the length of attaching mandrel of each pass (the distance between the adjacent two start points in the contour line) can be achieved. 


\subsection{Determination of the roller path profile}

The roller path profile is determined by calculating the position point by point based on a rule of circumferential strain distribution. As previously mentioned, the roller path in conventional spinning is composed of the attaching mandrel section and the preforming section, and the preforming section is further divided into the attaching mandrel section in next pass (AMSNP) and the non-attaching mandrel section in next pass (NMSNP). The profile of attaching mandrel section is designed according to the component contour, and the length of attaching mandrel section is described in Fig. 3 (b) in section 2.2. This section mainly introduces how to calculate the roller path profile of the preforming section based on the distribution of circumferential strain in each pass. The flow chart of calculation of roller path profile is shown in Fig. 4. In the first pass, there is only the preforming section. The rest of circumferential strain $\left\{\varepsilon_{\theta 1 i}\right\}$ to produce the final TCPCS is calculated point by point, and then the roller path profile is determined by distributing the circumferential strain. Except for the first pass, the roller path profile of the remaining passes include the attaching mandrel section and the preforming section. Under this condition, the coordinate translation caused by the attaching mandrel section should be considered when calculating $\left\{\varepsilon_{\theta n i}\right\}$.The detail procedure is as follows. 


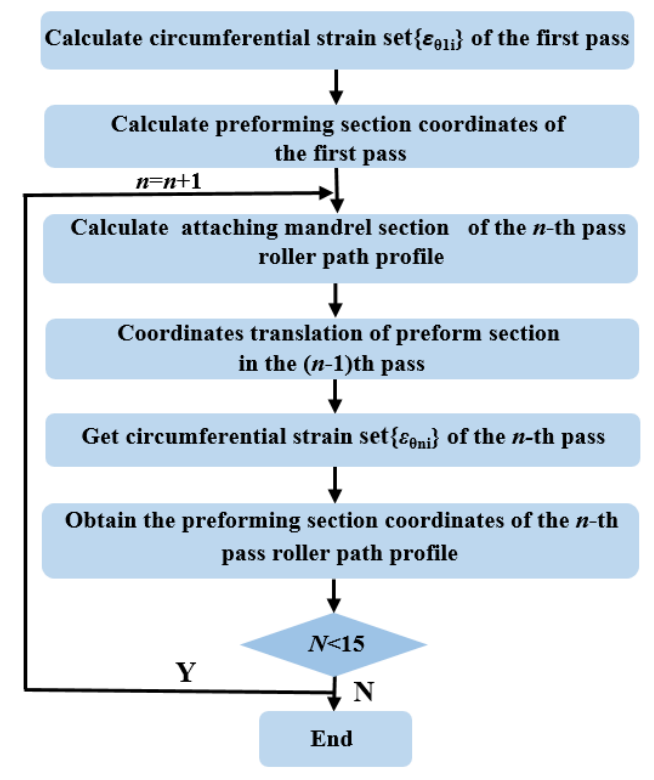

Fig. 4 Flow chart of the calculation of roller path profile

The roller path profile of the first pass preforming section is achieved by calculating the coordinates point by point under a principle of circumferential strain distribution. As shown in Fig. 5. The workpiece edges is a flat state at the beginning of the conventional spinning, and the rest of circumferential strain $\left\{\varepsilon_{\theta 1 i}\right\}$ to produce the final TCPCS is shown in Fig. 3 (a). The wall thickness is assumed to be constant during deformation $\left(t_{0}=t\right)$. Let the roller path coordinates set of the first pass is $\left\{\left(x_{10}, y_{10}\right),\left(x_{11}, y_{11}\right) \ldots \ldots\left(x_{1 \mathrm{i}}, y_{1 \mathrm{i}}\right) \ldots \ldots\right\}$, in which the " 1 ” in the first subscript represents the first pass, and the " $\mathrm{i}$ " in the second subscript indicates the $i$-th point of the first pass. The corresponding point coordinates on the workpiece $\operatorname{are}\left\{\left(x_{10}^{\prime}, y_{10}^{\prime}\right),\left(x_{11}^{\prime}, y_{11}^{\prime}\right) \ldots \ldots\left(x_{11}^{\prime}, y_{1 i}^{\prime}\right) \ldots \ldots\right\}$. Similar to 2.2 , according to the principle of volume invariance during deformation, Eq. (6) can be achieved. The expression of $y_{1 \mathrm{i}}$ can be obtained as shown in Eq. (7). Since there is the same starting point of the workpiece and roller path, the boundary condition can be obtained as shown in Eq. (8). Based on Eq. (4) and assuming the deformation amount of the workpiece is $\alpha\left\{\varepsilon_{\theta 11}\right\}$ from flat state to finished the first pass state, the expression of $x_{1 \mathrm{i}}$ can be derived as shown in Eq. (9). When $\alpha$ in Eq. (9) is determined, the first pass roller path profile can be obtained. 


$$
\begin{gathered}
\left(x_{1 \mathrm{i}}^{\prime 2}-x_{1(\mathrm{i}-1)}^{\prime 2}\right) t_{0} \pi=\pi t \sqrt{\left(x_{1 \mathrm{i}}-x_{1(\mathrm{i}-1)}\right)^{2}+\left(y_{1 \mathrm{i}}-y_{1(\mathrm{i}-1)}\right)^{2}} \times\left(x_{1 \mathrm{i}}+x_{1(\mathrm{i}-1)}\right) \\
y_{1 \mathrm{i}}=-\sqrt{\frac{x_{1 \mathrm{i}}^{\prime 2}-x_{1(\mathrm{i}-1)}^{\prime 2}}{x_{1 \mathrm{i}}+x_{1(\mathrm{i}-1)}}-\left(x_{1 \mathrm{i}}-x_{1(\mathrm{i}-1)}\right)^{2}}+y_{1(\mathrm{i}-1)} \\
x_{10}=x_{10}^{\prime}, y_{10}=y_{10}^{\prime} \\
x_{1 \mathrm{i}}=e^{\alpha \varepsilon_{\theta 1 \mathrm{i}}+\ln x_{1 \mathrm{i}}^{\prime}}
\end{gathered}
$$

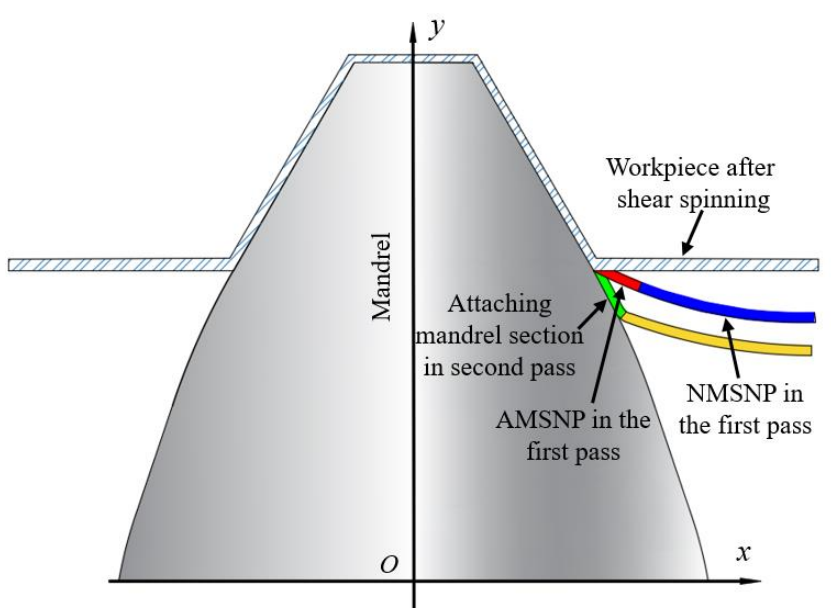

Fig. 5 Schematic diagram of the roller path for the first spinning pass

The distribution of circumferential strain is reflected in the value of $\alpha \varepsilon_{\theta 1 \mathrm{i}}$ in Eq. (9), which is determined according to the following rules. The equal circumferential strain distribution in each pass is beneficial to get uniform wall thickness [15].Therefore, the $\alpha$ is set as 0.5 in the AMSNP,which means the circumferential strain of this section is evenly distributed in two passes(AMSNP in the first pass and the attaching mandrel section in the second pass), as shown in Fig 5. Because the length of attaching mandrel section is obtained according to the equal ultimate circumferential strain 0.025 , the circumferential strain at the end of the AMSNP is 0.0125 when $\alpha$ is 0.5 . For the NMSNP in the first pass, in order to make the forming process stability, the value of $\alpha \varepsilon_{\theta 1 \mathrm{i}}$ is taken as 0.0125 , namely the half of ultimate circumferential strain $\varepsilon_{\theta u l t}$, which is the same as the circumferential strain at the end of the AMSNP in the first pass. Then, the point by point coordinates of the first pass can be obtained based on the above circumferential strain distribution rule. 
The roller path design method of other passes is same as the first pass expect the calculation of $\left\{\varepsilon_{\theta \mathrm{ni}}\right\}$. According to the method of calculating $\left\{\varepsilon_{\theta 11}, \varepsilon_{\theta 12} \ldots \ldots \varepsilon_{\theta 1 \mathrm{i}} \ldots \ldots\right\}$ described in 2.2 , the set $\left\{\varepsilon_{\theta \mathrm{n} 1}\right.$, $\left.\varepsilon_{\theta \mathrm{n} 2} \ldots \ldots \varepsilon_{\theta \mathrm{ni}} \ldots \ldots\right\}$ applied in the calculation of the roller path profile in AMSNP section can be obtained, where $n$ is the number of passes. Taking the roller path design of the second pass as an example. In the spinning process, when the attaching mandrel section is completed in the second pass, the position of NMSNP in the first pass will move to yellow line as shown in Fig. 6 . The $\left\{\varepsilon_{\theta 2 i}\right\}$ represents the point ${ }^{-}$bypoint circumferential strain generated in the process that the workpiece after finishing attaching mandrel in second pass is formed into final TCPCS. Thus, when calculate the point-by-point $\left\{\varepsilon_{\theta 2 i}\right\}$, the initial position of workpiece should be considered as the position of yellow line, which can be obtained by moving the position of NMSNP in the first pass. Similarly, the calculation of the rest circumferential strain $\left\{\varepsilon_{\theta n i}\right\}$ of the $n$-th pass need to consider the position change of (n-1)th NMSNP after attaching mandrel in the n-th pass. Considering the above noteworthy points, the remaining steps for calculating the roller path profile of the second pass is calculated according to the method of first roller path profile and the details are as follows. The attaching mandrel section profile is same as the mandrel. For preforming section profile, when the second pass attaching mandrel is completed, let the preforming section of the second pass is described by the following points set $\left\{\left(x_{20}, y_{20}\right),\left(x_{21}, y_{21}\right)\right.$, $\left.\left(x_{22}, y_{22}\right) \ldots \ldots\left(x_{21}, y_{2 \mathrm{i}}\right) \ldots \ldots\right\}$, and the coordinates of the corresponding in yellow line are represented by the points set: $\left\{\left(x_{20}^{\prime}, y_{20}^{\prime}\right),\left(x_{21}^{\prime}, y_{21}^{\prime}\right),\left(x_{22}^{\prime}, y_{22}^{\prime}\right) \ldots \ldots\left(x_{2 \mathrm{i}}^{\prime}, y_{2 \mathrm{i}}^{\prime}\right) \ldots \ldots\right\}$. Similarly, it is assumed that the wall thickness is unchanged before and after deformation $\left(t_{2}=t_{2^{\prime}}\right)$. Eq. (10) can be obtained in any small deformation region depending on constant volume principle. The expression of $y_{2 \mathrm{i}}, x_{2 \mathrm{i}}$ and the boundary condition are shown in Eq. (11),(12),(13) and (14), respectively. The roller path coordinates is achieved by determining the $\lambda \varepsilon_{\theta 2 \mathrm{i}}$ value. The circumferential strain distribution rule is the same as that of the 
first pass. The roller path profile calculation method of 3-15 passes is the same as the second pass.

According to the above steps, the designed 15 passes roller path is obtained and shown in Fig. 7.

$\left.\pi t_{2} \sqrt{\left(x_{2 \mathrm{i}}-x_{2(\mathrm{i}-1)}\right)^{2}+\left(y_{2 \mathrm{i}}-y_{2(\mathrm{i}-1)}\right)}\right)^{2}\left(x_{2 \mathrm{i}}+x_{2(\mathrm{i}-1)}\right)=\pi t_{2^{\prime}} \sqrt{\left(x_{2 \mathrm{i}}^{\prime}-x_{2(\mathrm{i}-1)}^{\prime}\right)^{2}+\left(y_{2 \mathrm{i}}^{\prime}-y_{2(\mathrm{i}-1)}^{\prime}\right)^{2}}\left(x_{2 \mathrm{i}}^{\prime}+x_{2(i-1)}^{\prime}\right)$

(10)

$$
\begin{aligned}
& \left.a=\sqrt{\left(x_{2 \mathrm{i}}-x_{2(\mathrm{i}-1)}\right)^{2}+\left(y_{2 \mathrm{i}}-y_{2(\mathrm{i}-1)}\right)}\right)^{2}\left(x_{2 \mathrm{i}}+x_{2(\mathrm{i}-1)}\right) \\
& y_{\mathrm{i}}^{2}=-\sqrt{\left[\frac{a}{x_{2 \mathrm{i}}+x_{2(\mathrm{i}-1)}}\right]^{2}-\left(x_{2 \mathrm{i}}-x_{2(\mathrm{i}-1)}\right)^{2}}+y_{2(\mathrm{i}-1)} \\
& x_{\mathrm{i}}^{2}=e^{\alpha \varepsilon_{\theta 2 \mathrm{i}}+\ln x_{2 \mathrm{i}}^{\prime}} \\
& x_{20}=x_{20}^{\prime}, y_{20}=y_{20}^{\prime}
\end{aligned}
$$

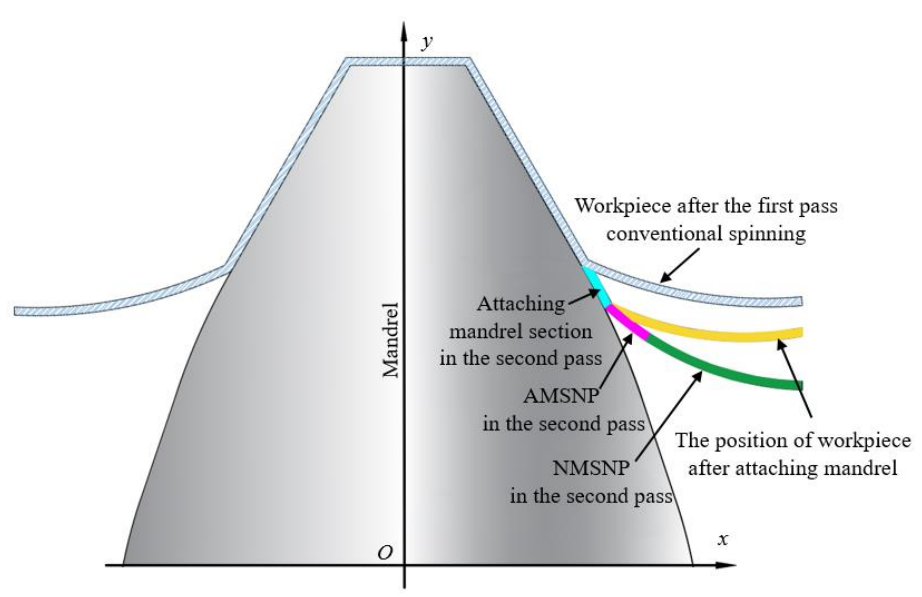

Fig. 6 Schematic diagram of the roller path for the second spinning pass

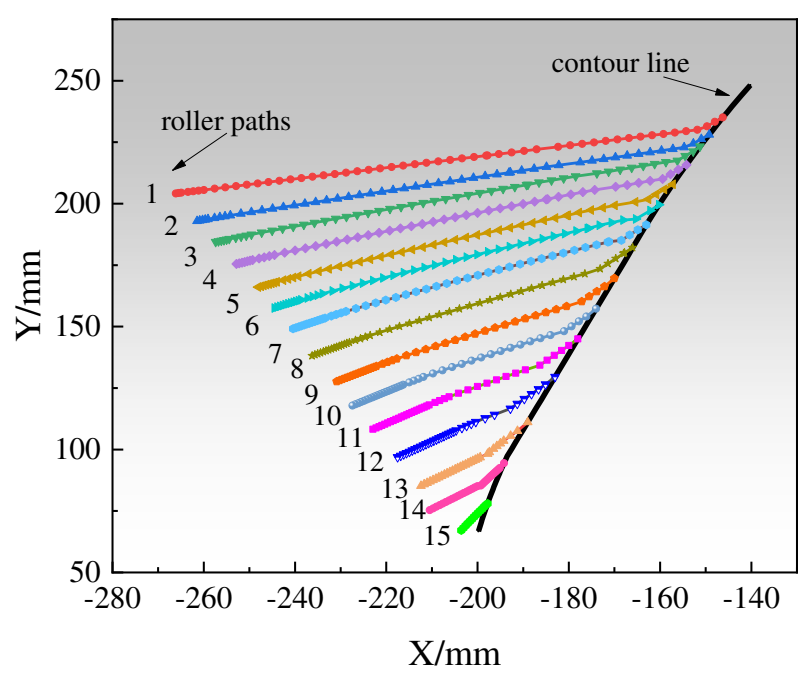

Fig. 7 The designed roller path based on circumferential strain distribution (RPCSD) $\alpha \alpha$ 


\section{Verification of the designed roller path}

The main purpose of this section is to prove the effectiveness of the roller path design method by simulating the spinning process of the superalloy TCPCS (shown in Fig 1). Therefore, it is necessary to establish a reliable spinning model [18]. Then the simulation results under the designed roller path are analyzed to illustrate the effectiveness of the design Method.

\subsection{FE model for conventional spinning of TCPCS}

The FE model for spinning of TCPCS is established by ABAQUS software. Considering the large deformation and complex contact conditions, the dynamic explicit algorithm is used. Fig. 8 (a) is the assembly drawing of TCPCS spinning model, in which the material is GH3128 superalloy with thickness of $1.6 \mathrm{~mm}$ and diameter of $540 \mathrm{~mm}$. The rollers and mandrel are defined as analytical rigid bodies, and the blank is deformation body. The material property parameters are selected according to the true stressstrain curve of GH3128 at $500{ }^{\circ} \mathrm{C}$. The deformation behavior is described by Hollomon hardening criterion: $\sigma=K \varepsilon^{\mathrm{n}}$ and the specific material parameters are shown in Table 1. In order to simulate the spinning process more accurate, 4-node curved shell element S4R is adopted as main element, as shown in Fig. 8(b). Meanwhile, the 3-node triangular shell element S3 is used as transition element. The size of element was controlled about one fifth of the roller radius. The blank and the mandrel fixed together by tie constraint to realize the rotation of blank under the drive of the mandrel. The Coulomb's friction law is applied to simulate the contact behavior between the spinning tools and blank. The contact friction coefficient of two contact pairs including mandrel-blank and roller-black is 0.02 . The model realizes the input of the roller path by the coordinate translation of the contact point relative to the reference point. 
Table 1. Mechanical properties of GH3128 superalloy at $500^{\circ} \mathrm{C}$

\begin{tabular}{lc}
\hline Material parameters & Values \\
\hline Young's modulus $E(\mathrm{GPa})$ & 169 \\
Poisson's ration $v$ & 0.3 \\
Strength coefficient $K(\mathrm{MPa})$ & 1611.32 \\
Hardening exponent $n$ & 0.51 \\
Density $\rho\left(\mathrm{g} / \mathrm{cm}^{3}\right)$ & 8.81 \\
\hline
\end{tabular}

The reliability of the model is verified by comparing the shape and wall thickness distribution between simulation and experiment under the same forming parameters. In the experiment the spinning roller path is composed of two sections, as shown in Fig. 8(c). The shear spinning section is a $30^{\circ}$ straight line, and the conventional spinning section is a concave curve. Based on experiments and literature research $[7,19,20]$, the specific parameters of the experiment are shown in Table 2. The feed ratio of the shear spinning section and the conventional spinning section is $1 \mathrm{~mm} / \mathrm{s}$ and $6 \mathrm{~mm} / \mathrm{s}$ respectively, and the spinning temperature is $500{ }^{\circ} \mathrm{C}$. Finite element simulation and corresponding experiments were carried out with the above parameters.

(a)

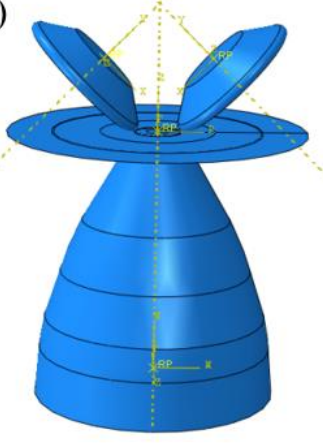

(b)

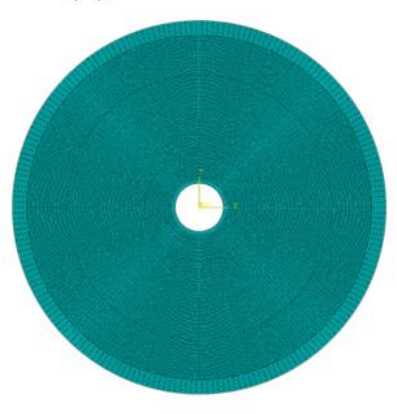

(c)

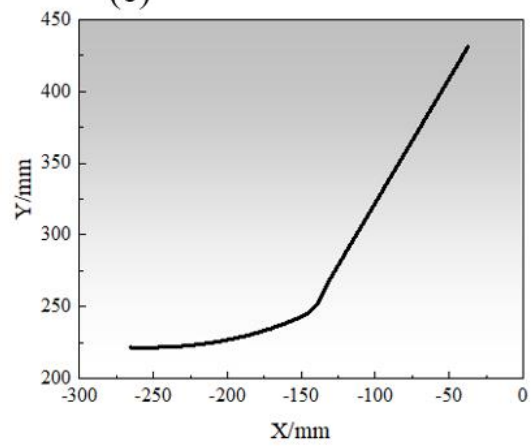

Fig. 8 Modeling description: (a) assembly drawing of TCPCS spinning model, (b) meshing diagram of blank and (c) spinning roller path. 
Table 2 Processing parameters in simulation and experiment

\begin{tabular}{lc}
\hline Basic parameters & Value \\
\hline Diameter $D(\mathrm{~mm})$ & 540 \\
Thickness $t_{0}(\mathrm{~mm})$ & 1.6 \\
Spinning speed $N(\mathrm{r} / \mathrm{min})$ & 60 \\
Shear spinning feed rate $f_{\mathrm{s}}(\mathrm{mm} / \mathrm{s})$ & 1 \\
Conventional spinning feed rate $f_{\mathrm{c}}(\mathrm{mm} / \mathrm{s})$ & 6 \\
The angle between the axis mandrel and the axis of roller & 45 \\
Nose radius of roller $r_{\mathrm{n}}(\mathrm{mm})$ & 10 \\
Diameter of roller $D_{\mathrm{w}}(\mathrm{mm})$ & 250 \\
Thickness of roller $H_{\mathrm{w}}(\mathrm{mm})$ & 40 \\
\hline
\end{tabular}

It can be seen from Fig. 9 (a) that the shape of the simulated workpiece is similar to the experimental one. Taking four generatrix with an interval of $90^{\circ}$ and calculating the average wall thickness at the same axial position, as shown in Fig. 9 (b), it can be found that the wall thickness distribution of the simulated and experimental parts presents a similar trend. The maximum thinning deviation and the average thinning deviation is $9.3 \%$ and $1.5 \%$ respectively. The above analysis shows that the established finite element model is reliable.

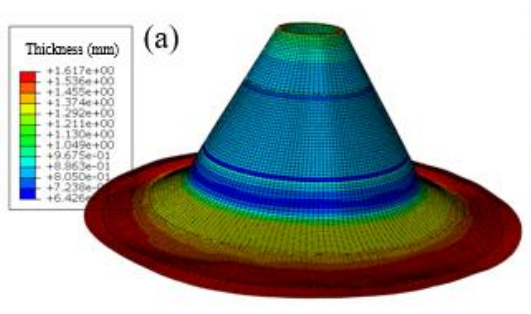

simulation specimen

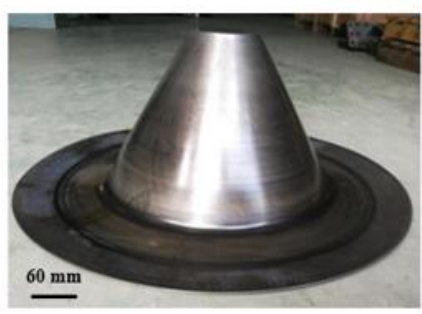

experimental specimen

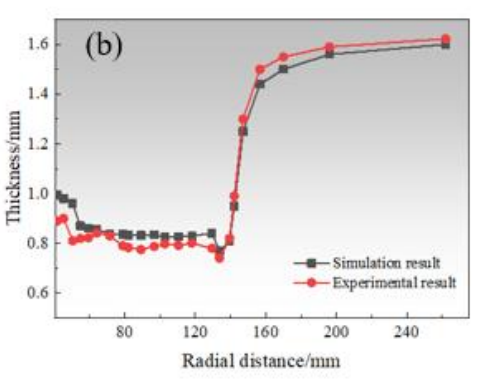

Fig. 9 Comparison of simulated and experimental results: (a) specimen shape; (b) wall thickness distribution. 


\subsection{Analysis of the forming result under designed roller path}

Based on the effective spinning model, the designed roller path RPCSD is used to simulate the spinning process. The effectiveness of the RPCSD is confirmed by analyzing the stability of the deformation process, the uniformity of wall thickness and roundness.

Fig. 10 (a), (b) showthe forming state after finishing the fifth and tenth pass respectively. It can be discovered that the flange has no wrinkling phenomenon, which is benefit to conventional spinning. The RPCSD can make the component forming stabilityand the final component is shown in Fig. 11(a).

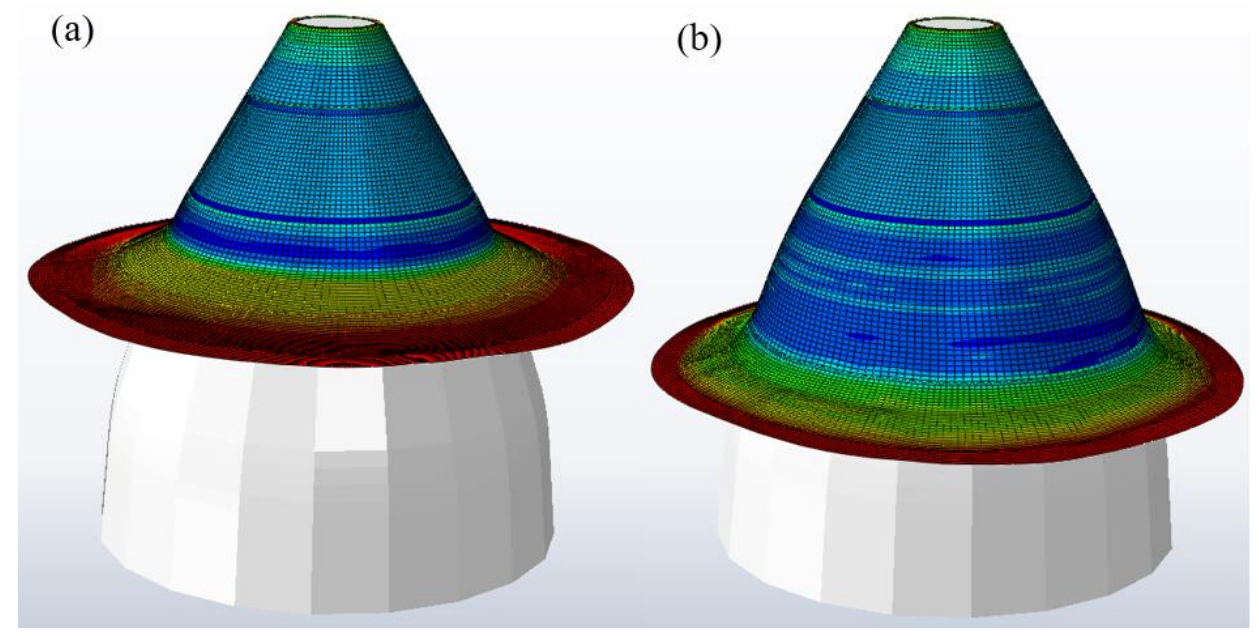

Fig. 10 Forming state of TCPCS: (a) the forming state after the fifth pass; (b) the forming state after the tenth pass.

Fig. 11(a) shows the simulation results using RPCSD. It can be seen that the wall thickness distributes within the range of $0.56-0.9 \mathrm{~mm}$. The distribution of wall thickness along the generatrix is shown in Fig. 11(b). It can be found that the wall thickness distribution is uniform and the average wall thickness is about $0.8 \mathrm{~mm}$ in the shear spinning section, which follows the sine law reduction. The wall thickness of conventional spinning section fluctuates in a certain range. While, the standard deviation is only $0.0035 \mathrm{~mm}$. The above analyses show that the wall thickness distribution is relatively uniform using RPCSD. 

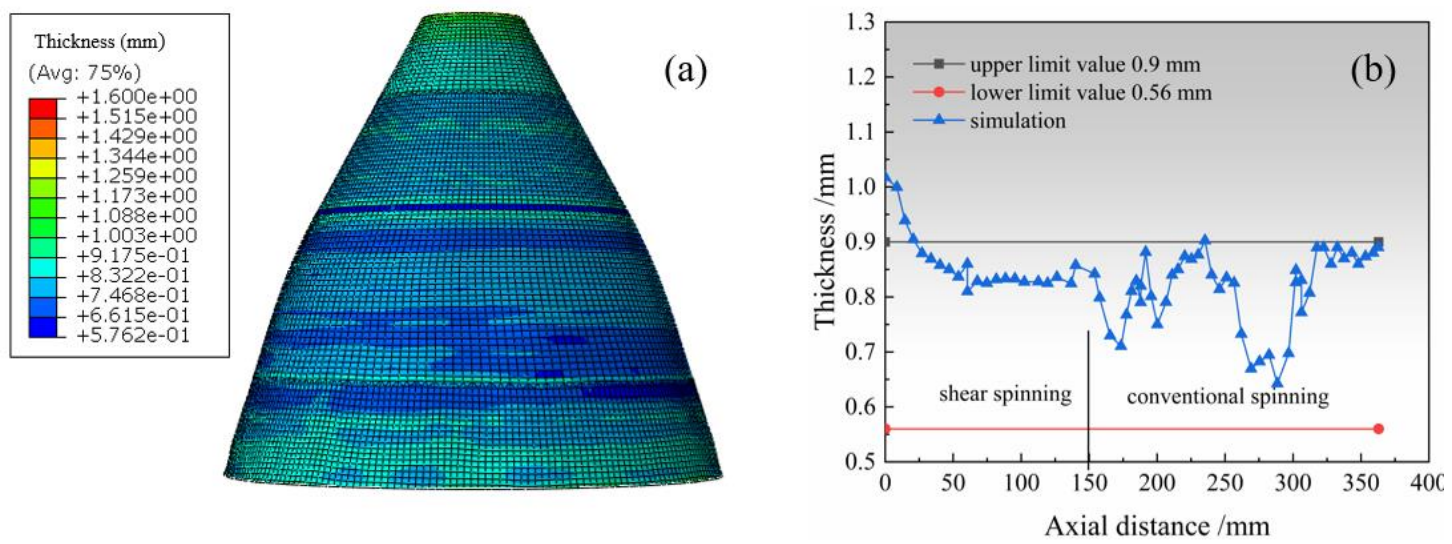

Fig. 11 Wall thickness distribution: (a) on the spun part; (b) along the axial.

Roundness of spun parts is also an important quality index. Taking sections with an interval of 10

$\mathrm{mm}$ along the axial direction to measure, the ratio of the minimum radius to the maximum radius is calculated to evaluate the roundness. Fig. 12 shows the distribution of roundness along the axial direction. It can be seen that the roundness decreases with the increase of axial distance, which means the roundness of workpiece gets worse a little. Thus, the roundness distribution is relatively uniform and well.

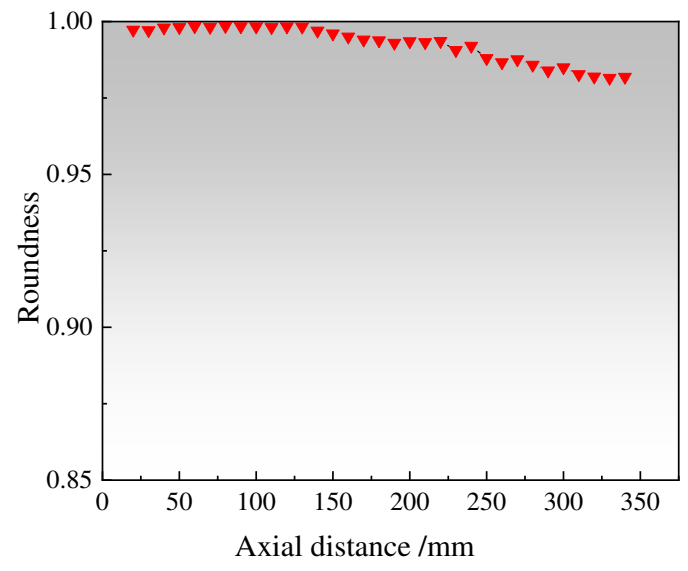

Fig. 12 Axial distribution of roundness

From the above analysis, it shows that the proposed design method for roller path in conventional spinning of TCPCS is effective. Moreover, this method has the following advantages: (1) it takes the deformation amount as the bridge to connect the roller path parameters and the geometry of the component together, which make the method has strong universality. (2)The roller path profile is obtained based on the distribution of the circumferential strain point by point, which doesn't depend on any type 
of curve.

\section{Conclusions}

In this paper, a quantitative investigation was conducted on the roller path design in the multi-pass conventional spinning of thin-walled conical part with curved surface (TCPCS). The following conclusions can be drawn:

(1) A new method based on circumferential strain distribution for the multi-pass roller path design for the conventional spinning of TCPCS was developed.

(2) The method contains three important steps: (a) determination of the spinning passes number according to the ultimate circumferential strain producing the spinning instability ( $\varepsilon_{\theta u l t}$ ); (b) determination the length and profile of the the attaching mandrel section which takes the same profile of mandrel and extends to the point that whose circumferential strain reaches the $\varepsilon_{\theta u l t}$; (c) the profile calculation of the preforming section through a point-by-point approach by distributing the rest of circumferential strain $\left\{\varepsilon_{\theta \mathrm{ni}}\right\}$ to produce the final TCPCS.

(3) Case application in the conventional spinning of a superalloy TCPCS suggests that the proposed new method of roller path is effective and can obtain well spinning stability, wall thickness distribution and roundness. Different from the traditional empirical trial-and-error design method, this new method is a quantitative, high-efficient and universal way for the multi-pass roller path design in conventional spinning of TCPCS.

\section{Acknowledgements}

This study is supported by National Natural Science Foundation of China (No. 92060107, No. U1737212) and National Major Science and Technology Projects of China (J2019-VII-0014-0154). The authors appreciate Dr Wei Lv, Zhenni Lei, Shuwan Chen, Yunda Dong, Rui Li, Hongrui Zhang, Zhiwei 
Yang and Xuechao Li of North-western Polytechnical University for their help in revising the article and related soft applications. The authors also appreciate the reviewers for their constructive suggestions.

\section{Author contribution}

Yongdi Wang conceived the method and wrote the manuscript. Pengfei Gao directed and improved the method, and put forward valuable suggestions for the writing of the article. Mei Zhan and Hongwei Li participated in article revision and provided project support. The contributions of Xinggang Yan and Haotong Niu lay in the discussion of previous methods and the inspection of manuscript, respectively. All authors discussed the results and commented on the manuscript.

\section{Declarations}

Ethics approval Not applicable.

Consent to participate Not applicable.

Consent for publication Not applicable.

Competing interests The authors declare no competing interests.

\section{References}

1. Lin YC, Deng J, Jiang Y-Q, Wen D-X, Liu G. (2014) Hot tensile deformation behaviors and fracture characteristics of a typical Ni-based superalloy. Mater Des 55:949-957. https://doi.org/10.1016/j.matdes.2013.10.071

2. Wong CC, Dean TA, Lin J. (2003) A review of spinning, shear forming and flow forming processes. Int J Mach Tool Manu 43:1419-1435. https://doi.org/10.1016/S0890-6955(03)00172-X

3. Xia Q, Xiao G, Long H, Cheng X, Sheng X. (2014) A review of process advancement of novel metal spinning. Int J Mach Tool Manu 85:100-121.

https://doi.org/10.1016/j.ijmachtools.2014.05.005

4. Chen SW, Gao PF, Zhan M, Ma F, Zhang HR, Xu RQ. (2019) Determination of formability considering wrinkling defect in first-pass conventional spinning with linear roller path. J Mater Process Tech 265:44-55. https://doi.org/10.1016/j.jmatprotec.2018.10.003

5. Wei ZC, Li WD, Wan M, Xu CX, Liu J. ( 2010) Influence of roller-trace on multi-pass conventional spinning process. Journal of Plasticity Engineering 17(3):108-112.

6. Music O, Allwood JM, Kawai K. (2010) A review of the mechanics of metal spinning. J Mater Process Tech 210:3-23. https://doi.org/10.1016/j.jmatprotec.2009.08.021 
7. Xiao Y, Han Z, Zhou S, Jia Z. (2020) Experimental study of asymmetric multi-pass spinning. Int J Adv Manuf Technol 110:667-679. https://doi.org/10.1007/s00170-020-05913-7

8. Liu JH, Yang H. (2003) Development of multi-process conventional spinning and research on roller-trace. Mech Sci Technol 22(5):805-807.

9. Liu JH, Yang H, Li YQ. (2002) A study of the stress and strain distributions of first-pass conventional spinning under different roller-traces. J Mater Process Tech 129:326-329.

https://doi.org/10.1016/S0924-0136(02)00682-9

10. Hayama M, Kudo H, Shinokura T. (2008) Study of the Pass Schedule in Conventional Simple Spinning. Bull JSME 73:1358-1365. https://doi.org/10.1299/jsme1958.13.1358

11. Wang L, Long H. (2011) A study of effects of roller path profiles on tool forces and part wall thickness variation in conventional metal spinning. J Mater Process Tech 211:2140-2151.

https://doi.org/10.1016/j.jmatprotec.2011.07.013

12. James A. Polyblank JMA. (2015) Parametric toolpath design in metal spinning. CIRP ANNManuf Techn 64(1):301-304. https://doi.org/10.1016/j.cirp.2015.04.077

13. Chen J, Wan M, Li W. (2008) Design of the involute trace of multi-pass conventional spinning and application in numerical simulation. Journal of Plasticity Engineering 015:53-57.

14. Liu X, Zhang Y. (1997) How to select the moving passes of the spinning roller. Journal of Plasticity Engineering 18:84-90.

15. Guo H, Wang J, Lu G, Sang Z. (2017) A study of multi-pass scheduling methods for die-less spinning. Journal of Zhejiang University Science A 18:413-429. https://doi.org/10.1631/jzus.A1600403

16. Gao L, Song J, Zhao Y, Yu Z. (2021) Parametric roller path design in multi-pass conventional spinning of curvilinear generatrix parts. Int J Adv Manuf Technol 113:1637-1648. https://doi.org/10.1007/s00170-020-06556-4

17. Huang Y, Lu B, Chen J. (2017) A parametric tool path design in muti -pass asymmetric spinning. Journal of Shang Hai Jiao Tong University 51:1328-1333.

18. Wang L, Long H. (2011) Investigation of material deformation in multi-pass conventional metal spinning. Mater Des 32:2891-2899. https://doi.org/10.1016/j.matdes.2010.12.021

19. Wang L, Long H. (2013) Roller path design by tool compensation in multi-pass conventional spinning. Mater Des 46:645-653. https://doi.org/10.1016/j.matdes.2012.10.048

20. Zhan M, Gao P, editors.(2022)Conventional Spinning of Sheet Metals for Fabrication of Metallic Parts and Structures, pp. 197-213.https://doi.org/10.1016/B978-0-12-819726-4.00019-3 